\title{
Non-Answered Questions in Patients with Endobronchial Valve Placement for Lung Volume Reduction
}

\author{
Iván R. Caviedes ${ }^{a}$ Gonzalo Labarca $^{\text {b, c }}$ Hugo G. de Oliveira ${ }^{d}$ Felix J.F. Herth ${ }^{e}$ \\ Sebastián Fernandez-Bussy ${ }^{a}$ \\ aUnit of Interventional Pulmonology, Clínica Alemana de Santiago, Facultad de Medicina Clínica Alemana -

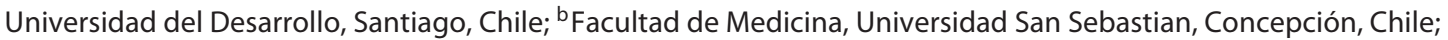 \\ 'Departamento Medicina Interna, Complejo Asistencial Dr. Víctor Ríos Ruiz, Los Ángeles, Chile; dUnidade de \\ Endoscopia, Universidad Federal do Rio Grande do Sul - UFRGS Respiratória Hospital de Clínicas de Porto Alegre - \\ HCPA, Porto Alegre, Brazil; e Department of Pneumology and Critical Care Medicine, Thoraxklinik, University of \\ Heidelberg, Heidelberg, Germany
}

\section{Established Facts}

- Pneumothorax is a common complication after endoscopic lung volume reduction (ELVR) and usually occurs in the first $48 \mathrm{~h}$ after endobronchial valve placement.

- Bronchial kinking is an uncommon complication and is actually treated with valve removal.

\section{Novel Insights}

- Complete kinking of the left lower lobe bronchus is a severe complication of left upper lobe ELVR.

- Patients' condition may worsen after treatment, even after achieving complete atelectasis of the target lobe.

- It is also uncommon for a patient to develop a pneumothorax on the 6th day after endobronchial valve placement.

\section{Keywords}

Chronic obstructive pulmonary disease - Endoscopic lung volume reduction $\cdot$ Pneumothorax $\cdot$ Severe hyperinflation

\section{Abstract \\ Endoscopic lung volume reduction is a minimally invasive procedure performed to reduce the space occupied by the emphysemas' lobes. This procedure has been demonstrat-}

ed to be beneficial for patients with advanced chronic obstructive pulmonary disease and severe hyperinflation. The use of endobronchial valves is increasing, as well as the number of reports of adverse events. The most common complications after the procedure are a pneumothorax, bleeding, infections, the need for valve removal, and valve expulsion. We have recently treated a patient who achieved immediate left upper lobe atelectasis but developed a pneumothorax on the 6 th day and near-fatal kinking of the

\section{KARGER}

(c) 2018 S. Karger AG, Basel

E-Mail karger@karger.com

www.karger.com/res
Iván R. Caviedes, MD

Unit of Interventional Pulmonology, Clínica Alemana de Santiago

Facultad de Medicina Clínica Alemana - Universidad del Desarrollo

Av. Vitacura 5951, Santiago 6681920 (Chile)

E-Mail icaviedes@alemana.cl 
left lower lobe bronchus. This patient had asphyctic episodes probably due to a functional left pneumonectomy. We should consider this unusual complication in patients undergoing endoscopic lung volume reduction whose condition worsens after achieving complete lobar atelectasis.

(c) 2018 S. Karger AG, Basel

\section{Introduction}

Endoscopic lung volume reduction (ELVR) with endobronchial valves has been demonstrated to be beneficial in patients with advanced emphysema. This procedure helps to improve pulmonary function, exercise tolerance, and symptoms [1] albeit with certain complications described in the literature. The benefits of this type of treatment are seen in patients without collateral ventilation. The VENT study [2] identified a subgroup of patients that may benefit from valves: complete interlobar fissure, no collateral ventilation, and complete occlusion of the target lobe. High-resolution computed tomography (HRCT) together with dedicated software (e.g., VIDA System) can be used to evaluate whether an interlobar fissure is complete or incomplete. Furthermore, the Chartis ${ }^{\circledR}$ system [3] can be used to determine the resistance to ventilation after bronchoscopic balloon occlusion of the target lobe. Thereby it increases the predictability of achieving lung volume reduction after valve treatment [4].

The relatively high morbidity and mortality rates associated with lung volume reduction surgery were the main drivers to develop ELVR techniques $[1,2,4,5]$.

\section{Case Report}

Our patient is a 67-year-old male, former smoker, with severe lung emphysema and dyspnea MRC 3. His pulmonary function tests showed FVC: $2.63 \mathrm{~L}$ (58.49\% of predicted), FEV1: $0.72 \mathrm{~L}$ (20.11\% of predicted), and VEF1/CVF: $27.25 \%$. TLC was $10.23 \mathrm{~L}$ ( $138.6 \%$ of predicted), RV was $7.07 \mathrm{~L}$ ( $270.3 \%$ of predicted), RV/ TLC was $60.09 \%$, and IC/TLC was $22 \%$. DLCO was $6.43 \mathrm{ml} / \mathrm{mm}$ $\mathrm{Hg} / \mathrm{min}$ (19\% of predicted), and 6MWT was $428 \mathrm{~m}$, with dyspnea Borg 4, and oxygen saturation down to 79\% (basal 95\% with Oxygen 2 Lx' by nasal prongs). His CT scan demonstrated severe and bullous emphysema with upper lobe predominance. VIDA ${ }^{\circledR}$ system demonstrated complete left fissure (integrity of 98\%) and an estimated left upper lobe volume of $2.67 \mathrm{~L}$ (left lung: $4.76 \mathrm{~L}$ ). $\mathrm{He}$ had a limited quality of life, and he was on LABA, LAMA, and oxygen therapy $24 \mathrm{~h}$ /day.

Before placing the valves, we used the Chartis system occluding the left upper lobe, demonstrating the complete absence of flow and increased resistance at $9 \min 50$ s. Five Zephyr ${ }^{\circledR}$ valves were placed, completely occluding the left upper lobe, a $4.0-\mathrm{mm}$ valve (\#3) LB1-2, a 5.5-mm valve (\#1) LB3, and a $4.0-\mathrm{mm}$ valve (\#1) LB4-5. A complete atelectasis of the upper lobe was immediately obtained, together with an elevation and restoration of the apposition zone of the diaphragm.

A remarkable relief of dyspnea and an increased walking capacity was observed during the first 2 days after the procedure. After that, our patient presented with tachycardia and increased oxygen requirements. The CT scan demonstrated diffuse left lower lobe alveolar opacities and a laminar pleural effusion. An ex vacuo overexpansion pulmonary edema was considered, and empirical diuretics were administered. The opacities resolved without other interventions in 4 days, the laminar pleural effusion persisted.

Six days after the valve placement, the patient complained of left-sided chest pain, chest X-ray demonstrated a tension pneumothorax, and drainage was placed. He suffered from continuous air leak for 4 days which finally resolved spontaneously. A moderate apical pneumothorax was still present together with a moderate pleural effusion. During the next day, sudden, repeated, asphyctic, and near-fatal crises were seen, which made emergency assistance by the team and noninvasive mechanical ventilatory support necessary. A CT scan of the thorax showed a persistent apical pneumothorax, a moderate pleural effusion, and suggested a kinking of the left lower lobe bronchus which was confirmed by the visualization of a narrowed bronchus by bronchoscopy (Fig. 1a). The LB4-5 valve was removed, but the asphyctic crisis continued. Finally, all valves were removed, and a complete re-expansion of the left upper lobe was observed. Bronchoscopy images and CT scan showed a straightening of the lower lobe bronchus (Fig. 1b). The respiratory asphyctic crisis resolved, and the patient is now almost back to baseline.

\section{Discussion}

ELVR is a noninvasive technique that improves symptoms, exercise tolerance, and pulmonary function in an appropriate candidate with advanced emphysema [1]. Endobronchial valve placement is a reversible technique that requires the absence of collateral ventilation to produce complete atelectasis of the target lobe and to achieve a meaningful clinical improvement.

An unexpected scenario is the absence of any clinical improvement after ELVR, even after achieving complete atelectasis of the target lobe, as was the case with our patient. The amount of volume reduction was not considered an issue, not even the magnitude of negative pressure induced by a lobar collapse. We report 2 major complications after valve placement: a late tension pneumothorax 6 days after the procedure (this usually occurs within the first 24-48 h), and a complete kinking of the left lower lobe bronchus.

In retrospect, the asphyctic crises were most likely secondary to a sudden functional left pneumonectomy due to complete atelectasis of the left upper lobe secondary to
Caviedes/Labarca/de Oliveira/Herth/ Fernandez-Bussy 

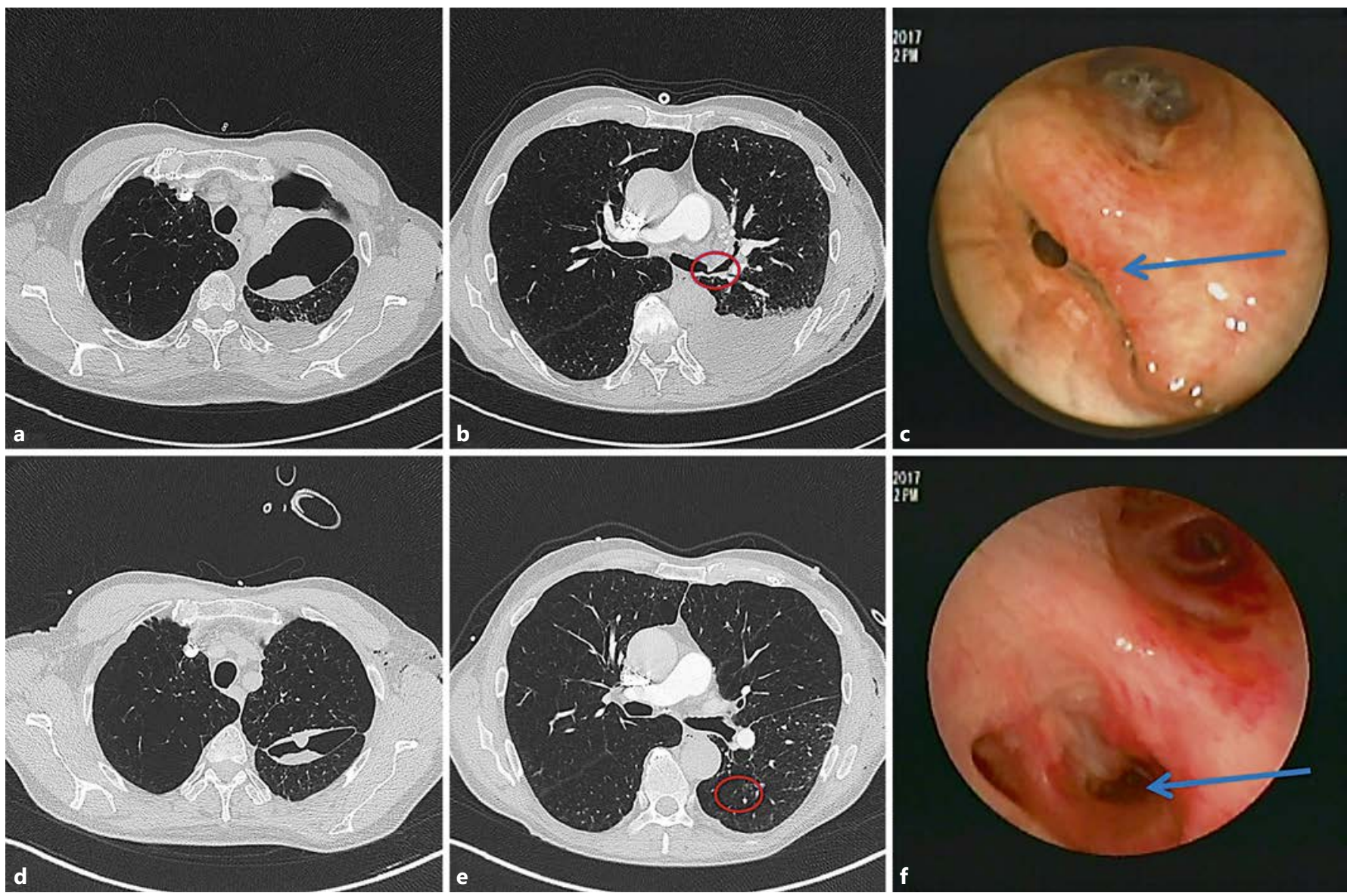

Fig. 1. a Left upper lobe (LUL) complete atelectasis after endobronchial valve placement. Complete collapsed and severe left lower lobe (LLL) bronchial kinking and pneumothorax (PTX). b Kinking of the LLL bronchus. c Narrowing LLL due to kinking. d LUL re-expansion with resolving PTX after all valves have been removed and bronchial kinking has resolved. e LLL bronchus open, kinking has resolved. f LLL bronchus open, kinking has resolved. endobronchial valve placement plus severe kinking of the left lower lobe bronchus. His previously estimated left upper lobe volume was $2.67 \mathrm{~L}$ by the VIDA system, and to our knowledge, this patient presented one of the largest reductions in lung volume reported after ELVR [6].

It is important to consider bronchial kinking in a patient whose condition worsens even after achieving complete lobar collapse. A CT scan and/or follow-up bronchoscopy are recommended for diagnosis. The removal of one or all valves may be necessary to correct this architectural deformity and improve the patient's symptoms. We do not know if the late-onset pneumothorax had any correlation with the bronchial kinking. In our case, the outcome of the procedure was unsuccessful, and we believe some specific questions about complications in pa- tients with complete interlobar fissure need to be discussed with the aim to optimize the procedure [7-9]. Finally, we propose the interventional pulmonary community to analyze a few questions that remain to be answered:

1. In cases of nearly complete lobar fissure (98\%), as determined by the VIDA system, is it necessary to confirm this with the Chartis system? Could the sudden lobar occlusion by a Chartis balloon be a risk factor for a tension pneumothorax?

2. What is the ideal or expected reduction in residual volume to obtain a clinically meaningful response? In comparison with ELVR publications, we obtained one of the largest reductions of volume reported. Do we really need to reduce higher volumes to clinically improve the outcome of these patients? 
3. Can kinking of a lobar bronchus be an indicator of a near-fatal complication, and should - in that case - all valves be immediately removed? Is stenting or positive pressure ventilation useful for bronchial kinking after ELVR?

4. In high-volume target lobes, should all valves be placed at once or in sequential procedures?

5. Should we always rule out bronchial kinking in patients with no clinical improvement after complete atelectasis of the target lobe following valve placement? These concerns should stimulate the discussion between interventional pulmonologists, in order to develop a safer and more effective procedure that will benefit our patients.

\section{Financial Disclosure and Conflicts of Interest}

The authors report no conflicts of interest.

\section{Author Contributions}

Dr. Caviedes, Dr. Labarca, and Dr. Fernandez-Bussy: concept, data extraction, writing, and final approval. Dr. de Oliveira and Dr. Herth: critical analysis, writing, and final approval.

\section{References}

1 Gompelmann D, Eberhardt R, Herth F: Endoscopic volume reduction in COPD - a critical review. Dtsch Arztebl Int 2014;111:827-833.

$>_{2}$ Sciurba FC, Ernst A, Herth FJ, Strange C, Criner GJ, Marquette CH, Kovitz KL, Chiacchierini RP, Goldin J, McLennan G; VENT Study Research Group: A randomized study of endobronchial valves for advanced emphysema. N Engl J Med 2010;363:1233-1244.

3 Herth FJ, Eberhardt R, Gompelmann D, Ficker JH, Wagner M, Ek L, Schmidt B, Slebos DJ: Radiological and clinical outcomes of using Chartis to plan endobronchial valve treatment. Eur Respir J 2013;41:302-308.
4 Shah PL, Herth FJ: Current status of bronchoscopic lung volume reduction with endobronchial valves. Thorax 2014;69:280-286.

5 Iftikhar IH, McGuire FR, Musani AI: Predictors of efficacy for endobronchial valves in bronchoscopic lung volume reduction: a meta-analysis. Chron Respir Dis 2014;11: 237-245.

6 Slebos DJ, Shah PL, Herth FJ, Valipour A: Endobronchial valves for endoscopic lung volume reduction: best practice recommendations from expert panel on endoscopic lung volume reduction. Respiration 2017;93:138150.

7 Valipour A, Slebos DJ, de Oliveira HG, Eberhardt R, Freitag L, Criner GJ, Herth FJ: Expert statement: pneumothorax associated with endoscopic valve therapy for emphysema - potential mechanisms, treatment algorithm, and case examples. Respiration 2014;87:513-521.
8 Davey C, Zoumot Z, Jordan S, McNulty WH, Carr DH, Hind MD, Hansell DM, Rubens MB, Banya W, Polkey MI, Shah PL, Hopkinson NS: Bronchoscopic lung volume reduction with endobronchial valves for patients with heterogeneous emphysema and intact interlobar fissures (the BeLieVeR-HIFi study): a randomised controlled trial. Lancet 2015;386:1066-1073.

-9 Klooster K, ten Hacken NH, Hartman JE, Kerstjens HA, van Rikxoort EM, Slebos DJ: Endobronchial valves for emphysema without interlobar collateral ventilation. $\mathrm{N}$ Engl J Med 2015;373:2325-2335. 